\section{Chronic kidney disease at primary care level: Significant challenges \\ remain}

To the Editor: Chronic kidney disease (CKD) remains a poorly recognised and ill-managed clinical entity. ${ }^{[1]}$ I reflect on three recent patient encounters at primary care level, hoping that these vignettes will serve to improve our clinical care of patients with, and at risk of developing, CKD.

Case 1. A 41-year-old man presented for routine 6-monthly followup of his hypertension and diabetes mellitus. His blood pressure (BP) had been significantly elevated on previous visits, and he was currently on four different antihypertensive agents. His serum creatinine level had been $120 \mu \mathrm{mol} / \mathrm{L}$ when last measured more than 2 years previously. He complained about worsening fatigue and occasional epigastric discomfort. Examination revealed a BP of 165/105 mmHg, conjuctival pallor and mild bipedal oedema. On evaluation of his renal function, his serum creatinine level was found to be $>2000 \mu \mathrm{mol} / \mathrm{L}$.

Case 2. A 46-year-old man complained of epigastric pain for 2 weeks. Further history taking revealed admission to an intensive care unit 18 months earlier, although no clinical information was available regarding that admission. Review of blood results from that time showed that he had presented with a serum creatinine level of $379 \mu \mathrm{mol} / \mathrm{L}$, which had improved to $305 \mu \mathrm{mol} / \mathrm{L}$ by the time of discharge. Blood tests had not been repeated since then. On systematic enquiry, the patient noted that he had recently been passing decreasing volumes of urine. Examination revealed a tender epigastrium but was otherwise unremarkable. His current serum creatinine level was $988 \mu \mathrm{mol} / \mathrm{L}$.

Case 3. A 40-year-old man presented with headaches, severe hypertension and a serum creatinine level of $886 \mu \mathrm{mol} / \mathrm{L}$. The clinical record showed that he had been seen 3 months earlier with the same clinical presentation. Although the creatinine level at that time had been $541 \mu \mathrm{mol} / \mathrm{L}$, this had not been acted on. Likewise, a creatinine level of $134 \mu \mathrm{mol} / \mathrm{L} 2$ years earlier had gone unnoticed.

All three patients were referred to the internal medicine department for further work-up and management.

There are several issues common to these three cases.

- Recognition of individuals at high risk for developing CKD and end-stage renal failure (ESRF) remains poor. Those with poorly controlled/resistant hypertension, poorly controlled diabetes mellitus and pre-existing episode(s) of acute kidney injury constitute a particularly high-risk group, and their renal function should be followed up diligently. This highlights the importance of following evidence-based guidelines for the management of such high-risk conditions. The 2014 South African (SA) hypertension practice guideline ${ }^{[2]}$ states that serum creatinine should be checked at least annually in hypertensive patients. None of the above patients had received such annual investigation, and the critical opportunity to detect and possibly delay the progression of their CKD had been missed.

- CKD progresses insidiously, and most patients are asymptomatic or present with 'minor' symptoms such as fatigue, swelling, weight loss and abdominal discomfort. This further highlights the importance of diligently screening for and appropriately managing CKD.

- Previous laboratory results should be routinely reviewed, as these may reveal important clinical information, e.g. previous renal dysfunction.

- Patients with abnormal renal function should ideally be considered for specialist referral - in all three of the cases described above, there had been significantly abnormal renal function in the preceding 18 - 24 months, yet none of the patients had been referred to an internist. Earlier detection of CKD, and appropriate referral, could aid in delaying the onset of ESRF.

In view of the fact that $\mathrm{SA}$ is currently able to offer renal replacement therapy to only $\sim 20 \%$ of patients requiring it, ${ }^{[1]}$ the early detection and prevention of ESRF is paramount. This places an important responsibility in the hands of primary care practitioners.

Guidance previously published in the $S A M J^{[3-5]}$ and elsewhere ${ }^{[6]}$ presents simple and useful approaches to the management and prevention of CKD. Following such guidance should aid in decreasing the burden of CKD and ESRF in SA communities.

\section{J Bovijn}

Community Service Medical Officer, South Africa

jonasbovijn@gmail.com

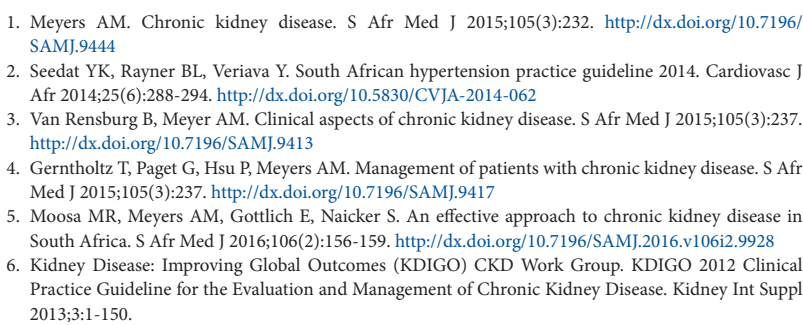
SAMJ. 944

2. Seedat YK, Rayner BL, Veriava Y. South African hypertension practice guideline 2014. Cardiovasc Afr 2014;25(6):288-294. http://dx.doi.org/10.5830/CVJA-2014-062

3. Van Rensburg B, Meyer AM. Clinical aspects of chronic kidney disease. S Afr Med J 2015;105(3):237. http://dx.doi.org/10.7196/SAMJ.9413

. Gerntholtz T, Paget G, Hsu P, Meyers AM. Management of patients with chronic kidney disease. S Afr Med J 2015;105(3):237. http://dx.doi.org/10.7196/SAMJ.9417

5. Moosa MR, Meyers AM, Gottlich E, Naicker S. An effective approach to chronic kidney disease in South Africa. S Afr Med J 2016;106(2):156-159. http://dx.doi.org/10.7196/SAMJ.2016.v106i2.9928

6. Kidney Disease: Improving Global Outcomes (KDIGO) CKD Work Group. KDIGO 2012 Clinica Kratey Disease: Improving Global Outcomes (KDIGO) CKD Work Group. KDIGO 2012 Clinica Practice Guideline for the Evaluation and Management of Chronic Kidney Disease. Kidney Int Supp
2013:3:1-150.

S Afr Med J 2017;107(3):171. DOI:10.7196/SAMJ.2017.v107i3.12292 